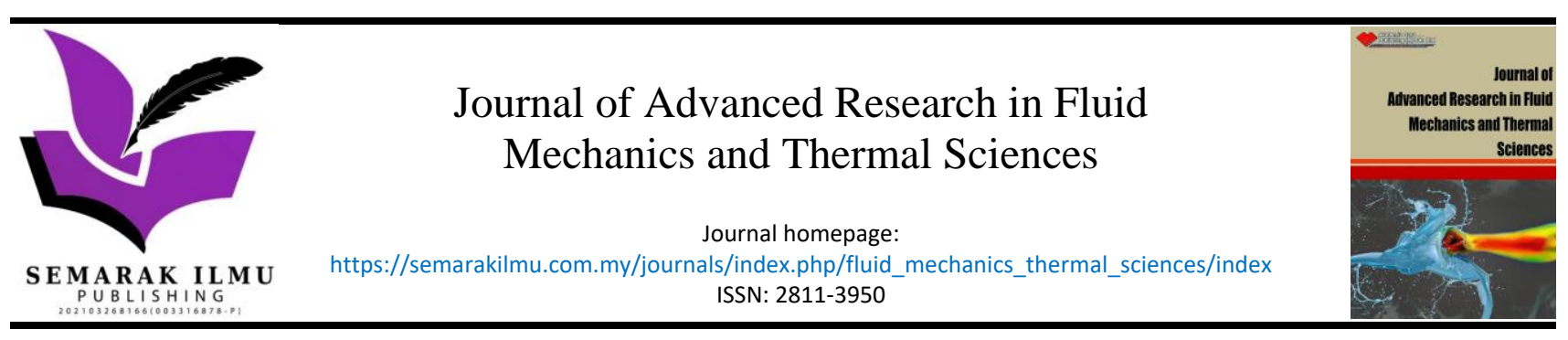

\title{
Heating Load of Residential Buildings Using Multiple Linear Regression Artificial Neural Network
}

\author{
Shafaf Ibrahim ${ }^{1,}{ }^{*}$, Saadi Ahmad Kamaruddin², Nor Anis Nadhirah Md Nasir ${ }^{3}$ \\ Faculty of Computer and Mathematical Sciences, Universiti Teknologi MARA, Jasin, Melaka, Malaysia \\ Centre of Testing, Measurement and Appraisal (CeTMA), Universiti Utara Malaysia, 06010, UUM Sintok, Kedah, Malaysia \\ Faculty of Civil Engineering Technology, Universiti Malaysia Perlis (UNIMAP), Kompleks Pusat Pengajian Jejawi 3, 02600, Arau, Perlis, Malaysia
}

\section{ARTICLE INFO}

\section{Article history:}

Received 7 October 2021

Received in revised form 25 December 2021

Accepted 9 January 2022

Available online 30 January 2022

\section{Keywords:}

Heating load; Residential buildings; Multiple Linear Regression; Artificial Neural Network

\section{ABSTRACT}

Global warming is one metric of climate change which is defined as an increase in the average global temperature. Residential buildings contribute significantly to the pollution that causes climate change. It is essential to have a comprehensive understanding of the functions of highly energy efficient buildings in view of projected climate projections, the quality of their heating systems, and the impact on human health and well-being. Thus, in this study, the effects of six input variables which are Overall Height, Glazing Area, Wall Area, Relative Compactness, Roof Area, and Glazing Area Distribution on one output variable, namely Heating Load (HL) of residential buildings was investigated using Multiple Linear Regression and Artificial Neural Network (MLR-ANN) approaches. Two-layer hyperbolic tangent-identity transfer functions with 63-1 configurations were employed as it was found as the best neural network model. A dataset of 768 residential buildings was used for secondary data. The Mean Square Error (MSE), determination coefficients $R^{2}$, as well as the percentage of normalized importance analysis were used to assess the statistical prediction capabilities of the MLRANN model. Based on the current findings, Wall Area is the most contributing factor towards HL, followed by Relative Compactness, Roof Area, Overall Height, Glazing Area, and Glazing Area Distribution. It can be suggested that HVAC (heating, ventilation, and air conditioning) systems should be implemented in residential buildings to reduce energy use. Natural ventilation is encouraged in buildings through vernacular design, and radiant heating and cooling systems as it is very effective and efficient way of providing thermal comfort within a structure.

\section{Introduction}

As the world facing global warming impact, architects are devising new ways to design buildings that load heat efficiently while mitigate environmental impact. It is critical to have a comprehensive overview of the functions of highly energy efficient buildings under climate projections, the quality of their heating systems, and the effect on human health and well-being of their residents [1]. In the United Kingdom, residential buildings accounted for almost $25 \%$ of greenhouse gas (GHG) final

\footnotetext{
* Corresponding author.

E-mail address: shafaf2429@uitm.edu.my
}

https://doi.org/10.37934/arfmts.92.1.2838 
emissions in 2012, prompting the UK government to pledge to an $80 \%$ reduction in GHG emissions by 2050 [2]. According to the Dean et al., [3], when upstream power generation is incorporated, buildings and construction contribute for $36 \%$ of total final energy use and $39 \%$ emission of carbon dioxide (CO2). Although progress toward more buildings and architecture that are environmentally sustainable are being developed the progress are still lagging behind with the booming construction industry and expanding demand for energy services.

Heating and cooling account for around $30-40 \%$ of the building's energy use. It is critical to initiate efforts to reduce surface temperatures in order to reduce total emission of greenhouse gases [4]. According to Tsanas and Xifara [5], the energy consumption of a structure varies depending on the climate, the building's purpose, design parameters, and operation conditions. Therefore, numerous new technique such as highly efficient equipment are being developed to improve building design based on a few factors including overall height, glazing area, wall area, relative compactness, roof area and glazing area distribution [6]. The calculation of the heating load $(\mathrm{HL})$ and cooling load $(\mathrm{CL})$ is essential in efficient building design to define the parameters for the heating and cooling equipment required to preserve a contented interior environment [4].

$\mathrm{HL}$ refers to the entire quantity of heat energy necessary to maintain a standard room temperature [7]. The HL prediction can assist heating operators in predicting heat demand and developing realistic operation plans [8]. At present, there are several research studies on the prediction of HL. Ding et al., [9] found that the HL of a structure is mostly impacted by external elements; however, considering interior variables may aid in the development of more accurate $\mathrm{HL}$ prediction models. Although heating load prediction is important for building development, the application of a cooling predicting model provides additional benefits for the system stability. Predicting heating and cooling load is important for a number of reasons, including reducing electricity consumption based on occupancy patterns, managing energy demands through the building's energy performance, lowering operational costs, and reducing hazardous gas emissions [10].

Liu et al., [11] stated that the prediction cycle for HL can be classified into three categories: immediate term, medium term, and longer - term. Forecasting the prospect in HL variations in the following 24 hours is referred to as short term prediction. Based on study by Ashouri et al., [12], temporal, autoregressive, and exogenous variables, has forecasted heating and cooling energy consumption in office buildings through hourly short-term modeling. Another study by Bacher et al., [13] forecasted the heat load during the following two days, as well as the hourly heat load for each house using this short term load prediction in sixteen houses located in Denmark. According to study by Dagdougui et al., [14], the best performance may be reached for one hour ahead of time. In general, medium-term HL forecasting refers to predicting the HL pattern for the upcoming week. A study by Ahmad and Chen [15], in the case of 14 days' period, the forecast performance was excellent in 7 days' period with the forecasting performance of the data mining (DM) model nearly sustain identical pattern. The average long-term prediction period is one year. Referring to Koschwitz et al., [16], when effects on long-term HL projections are taken into account, the analysis revealed that heat demand fluctuates over time according to different retrofit orders due to decreasing heat consumptions and building utilization interruptions throughout the retrofit process.

Several studies have attempted to successfully forecast the quantity of energy used in buildings through machine learning-based systems $[6,17,18]$. Artificial Neural Network (ANN) is one of these computer models that attempts to simulate the human brain's enormous cognitive and sensory capacities in order to use patterns to express and manipulate information [19]. It was established that the ANN had a higher level of precision in its predictions, proving that it outperformed other models [20]. Escandón et al., [21] concluded that the ANN has been successfully used to be a tool for 
assessing retrofitting techniques as it accurately forecasted thermal comfort using real-world data collected in-situ. Al-Habaibeh et al., [22] found that the neural network's outputs indicate great accuracy in forecasting actual energy savings when compared to estimated values, with a success rate of around $82 \%$. On the other hand, the Multiple Linear Regression (MLR) is one among the most extensively utilized machine learning methods in building energy load prediction [23].

Considering the most important elements is critical in developing an accurate HL forecast model [24]. Many external factors have an impact on district HL. It is critical to comprehend the various sorts of influence factors in order to eliminate redundancy or less relevant variables via several features in order to increase the model's explicability, computation speed, and accuracy, minimize noise, and avoid the risk of overfitting [25].

Controlling cooling and heating has always been seen as a component connected to both comfort and survival. Nevertheless, it is now regarded not as a luxury, but as a fact of modern living. Efforts to create cooling systems with the goal of preserving control of the environment in indoor areas of offices and residential buildings were visible in the worldwide setting at the beginning of the twentieth century. This first approach to achieving comfort levels in terms of cooling and heating results in what is today known as heating, ventilation, and air-conditioning (HVAC) [26].

Thus, a study on $\mathrm{HL}$ of residential buildings using Multiple Linear Regression and ANN (MLR-ANN) approaches is proposed. The remaining sections of the paper are organized as follows: The research method, as well as the data background and MLR-ANN structure, are detailed out in Section 2. In Section 3, we describe our results and discussions. Finally, we provide our conclusions and suggestions in Section 4.

\section{Methodology}

This research aims to establish a study for assessing the contributing factors of HL on residential buildings. A dataset of 768 residential buildings was downloaded from the study of Tsanas and Xifara [5]. Each of the 768 simulated buildings was characterized by six parameters which are Overall Height, Glazing Area, Wall Area, Relative Compactness, Roof Area, and Glazing Area Distribution. The data from descriptive statistics can be seen in Table 1.

Table 1

The descriptive statistics

\begin{tabular}{lllllllll}
\hline & & $\begin{array}{l}\text { Overall } \\
\text { Height }\end{array}$ & $\begin{array}{l}\text { Glazing } \\
\text { Area }\end{array}$ & Wall Area & $\begin{array}{l}\text { Relative } \\
\text { Compactness }\end{array}$ & Roof Area & $\begin{array}{l}\text { Glazing Area } \\
\text { Distribution }\end{array}$ & $\begin{array}{l}\text { Heating } \\
\text { Load }\end{array}$ \\
\hline $\mathrm{N}$ & Statistic & 768 & 768 & 768 & 768 & 768 & 768 & 768 \\
Range & Statistic & 3.5 & 0.4 & 171.5 & 0.36 & 110.25 & 5 & 37.09 \\
Minimum & Statistic & 3.5 & 0 & 245 & 0.62 & 110.25 & 0 & 6.01 \\
Maximum & Statistic & 7 & 0.4 & 416.5 & 0.98 & 220.5 & 5 & 43.1 \\
Sum & Statistic & 4032 & 180 & 244608 & 586.88 & 135632 & 2160 & 17131.93 \\
Mean & Statistic & 5.25 & 0.2344 & 318.5 & 0.7642 & 176.6042 & 2.81 & 22.3072 \\
& Std. Error & 0.06319 & 0.00481 & 1.57424 & 0.00382 & 1.62979 & 0.056 & 0.3641 \\
Std. & Statistic & 1.75114 & 0.13322 & 43.62648 & 0.10578 & 45.16595 & 1.551 & 10.0902 \\
Deviation & & & & & & & & \\
Variance & Statistic & 3.066 & 0.018 & 1903.27 & 0.011 & 2039.963 & 2.405 & 101.812 \\
Skewness & Statistic & 0 & -0.06 & 0.533 & 0.496 & -0.163 & -0.089 & 0.36 \\
& Std. Error & 0.088 & 0.088 & 0.088 & 0.088 & 0.088 & 0.088 & 0.088 \\
Kurtosis & Statistic & -2.005 & -1.328 & 0.117 & -0.707 & -1.777 & -1.149 & -1.246 \\
& Std. Error & 0.176 & 0.176 & 0.176 & 0.176 & 0.176 & 0.176 & 0.176 \\
\hline
\end{tabular}




\subsection{Multiple Linear Regression (MLR)}

MLR is known as regression models with a dependent variable and two or more independent variables. It is based on least-squares and is commonly used to assess the variable effects in a model $[27,28]$. In this study, MLR was performed on the training data set using $\mathrm{HL}$ as the response variable and the six predictor variables of Overall Height, Glazing Area, Wall Area, Relative Compactness, Roof Area, and Glazing Area Distribution. The outcome was expressed as a function of the six parameters in all cases.

\subsection{Artificial Neural Network (ANN)}

The ANN is one of the widely-known computational methods in Artificial Intelligence. It is a revolutionary computing system and approach that processes data or information and is inspired by the human nervous system [29]. The information processors, known as neurons, are the most important aspect of this computing system. A huge number of interconnected neurons made up the ANN system, which works collectively to solve a problem. The input layer, hidden layer, and output layer are the three layers that connect the input units to the outputs in most ANNs [30]. Different neural networks can be formed based on the arrangement of neurons and layer connection patterns. Multilayer Perceptron (MLP) and Radial Basis Function (RBF) neural networks are two of the most established neural networks, having a broad range of problem-solving applications [31].

In this study, the MLR-ANN approaches were implemented for the analysis. Table 2 summarizes the dependent and the independent variables in this study.

Table 2

The dependent and independent variables

\begin{tabular}{llll}
\hline Variable & Description & Notation & Type \\
\hline Dependent & Heating Load & HeatingLoad & Continuous \\
Independent & Overall Height & OverallHeight & Continuous \\
& Glazing Area & GlazingArea & Continuous \\
& Wall Area & WallArea & Continuous \\
& Relative Compactness & RelativeCompactness & Continuous \\
& Roof Area & RoofArea & Continuous \\
& Glazing Area Distribution & GlazingAreaDistribution & Continuous \\
\hline
\end{tabular}

The SPSS 23 was used to conduct the MLR-ANN analysis. A related approach can be seen in the studies by Ibrahim et al., [32], Mangshor et al., [33], and Ibrahim et al., [34]. The two-layer neural network is adapted using the hyperbolic tangent transfer function (Eq. (1)) in the first layer and the purelin transfer function (Eq. (2)) in the second layer as in the study by López-Aguilar et al., [35]. In Eq. (3), the general model of $\mathrm{HL}$ is depicted.

Hyperbolic tangent transfer, $Y_{i}=\frac{e^{X_{i}}-e^{-X_{i}}}{e^{X_{i}+e^{-X_{i}}}}$

and purelin, $Y_{j}=\sum_{i=1}^{m} W_{i j} Y_{i}+b_{j}$ 
where,

$m=$ number of neurons in output layer,

$W_{i j}=$ connections weight between layers $i$ and $j$,

$Y_{i}=$ outputs of neurons in layer $i$,

$X_{i}=$ inputs of neurons in layer $i$,

$b_{j}=$ bias of neurons in layer $j$.

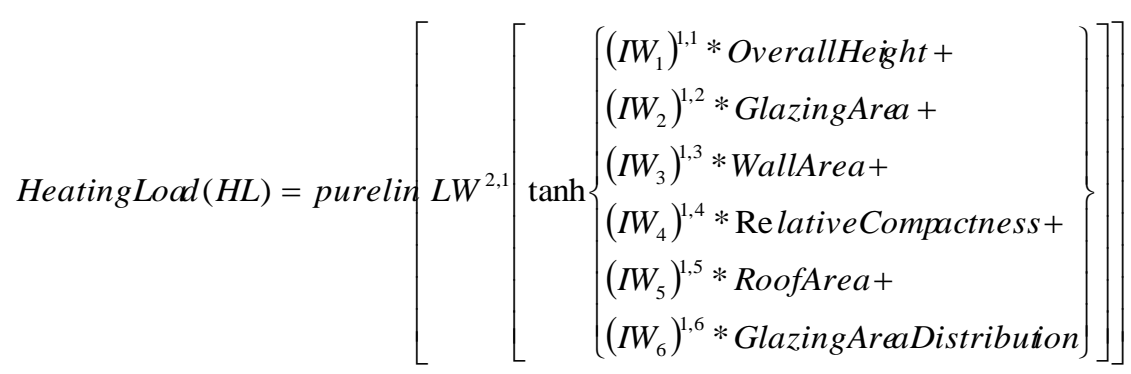

The data was separated into two sets during preprocessing which are training and testing. The total data, $N$ is 768, and no excluded data is reported. The training set contains $68.5 \%(526 / 768)$ of the total data, whereas, the test set contains $31.5 \%$ (242/768) of the total data. Six input variables of Overall Height, Glazing Area, Wall Area, Relative Compactness, Roof Area, and Glazing Area Distribution were included as covariates of the MLR-ANN network. The network has one hidden layer of three nodes of $H(1: 1), H(1: 2)$, and $H(1: 3)$. To simplify, the network's configuration was 6-3-1. The implemented network architecture is depicted in Figure 1.

The validation of the MLR-ANN in this study made use of the Mean Square Error (MSE) and the determination coefficient $\left(R^{2}\right)$ as presented in Eq. (4) and Eq. (5) respectively.

$M S E=\frac{\sum_{j=0}^{P} \sum_{i=0}^{N}\left(d_{i j}-y_{i j}\right)^{2}}{n P}$

where

$P=$ number of output neurons,

$n=$ sample size,

$y_{i j}$ and $d_{i j}=$ network output and desired output between layers $i$ and $j$.

$R^{2}=\left(\frac{\sum_{j}\left(X_{j}-\bar{X}\right)\left(d_{j}-\bar{d}\right)}{n}\right)^{2} / \frac{\sum_{j}\left(d_{j}-\bar{d}\right)^{2}}{n} \sqrt{\frac{\sum_{j}\left(X_{j}-\bar{X}\right)^{2}}{n}}$

where

$X_{j}=$ network outputs,

$\bar{X}=$ mean of the network outputs,

$d_{j}=$ desired outputs,

$d=$ mean of the desired outputs,

$n=$ sample size. 


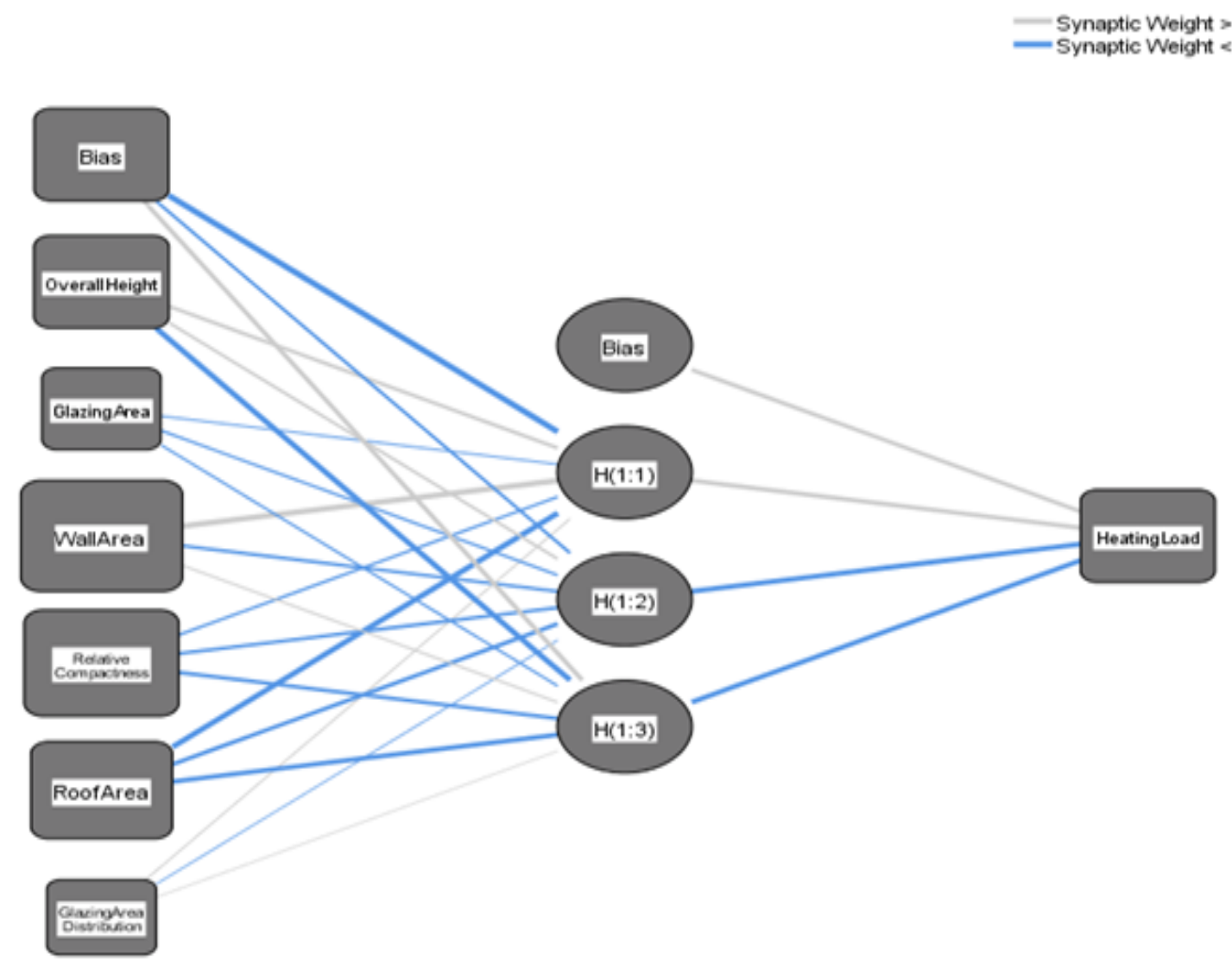

Hidden layer activation function: Hyperbolic tangent

Output layer activation function: Identity

Fig. 1. MLR-ANN Architecture for Heating Load of Residential Buildings

\section{Results}

The MSE and $R^{2}$ metrics were analyzed to determine the best model. The MSE and $R^{2}$ are the basic metrics for estimating statistical performance, which are used to assess the precision of the proposed models' predictive capacity [36]. Table 3 and Table 4 tabulate the best MLR-ANN model summary with $R^{2}$ value equals to 0.916 and residual MSE equals to 8.600. These data were statistically analyzed, and the following conclusions were reached: the determination coefficient $R^{2}$, an indicative of the goodness of the model fitting, is close to $92 \%$. The model attempted to address less than $8 \%$ of total variances, indicating that it provides a good approximation. By calculating the data explained by the model, the $R^{2}$ describes the variance amount. Indeed, $R^{2}=0.916$ is very near to 1 , indicating lower error variance [37].

\section{Table 3}

The model summary

\begin{tabular}{|c|c|c|c|c|c|c|c|c|c|c|}
\hline \multirow[t]{3}{*}{ Model } & \multirow[t]{3}{*}{$R$} & \multirow{3}{*}{$\begin{array}{l}\mathrm{R} \\
\text { Square }\end{array}$} & \multirow{3}{*}{$\begin{array}{l}\text { Adjusted } \\
\text { R Square }\end{array}$} & \multirow{3}{*}{$\begin{array}{l}\text { Std. Error } \\
\text { of the } \\
\text { Estimate }\end{array}$} & \multicolumn{5}{|c|}{ Change Statistics } & \multirow{3}{*}{$\begin{array}{l}\text { Durbin- } \\
\text { Watson }\end{array}$} \\
\hline & & & & & R Square & $\mathrm{F}$ & df1 & $\mathrm{df} 2$ & Sig. $F$ & \\
\hline & & & & & Change & Change & & & Change & \\
\hline & $.957^{f}$ & .916 & .916 & 2.93251 & .001 & 8.505 & 1 & 761 & .004 & .654 \\
\hline
\end{tabular}

Predictors: (Constant), OverallHeight, GlazingArea, WallArea, RelativeCompactness, RoofArea, GlazingAreaDistribution Dependent Variable: HeatingLoad 
Table 4

The ANOVA ${ }^{a}$

\begin{tabular}{llllll}
\hline Model & Sum of Squares & df & Mean Square & F & Sig. \\
\hline Regression & 71545.554 & 6 & 11924.259 & 1386.608 & $.000^{\mathrm{a}}$ \\
Residual & 6544.289 & 761 & 8.600 & & \\
Total & 78089.842 & 767 & & & \\
\hline
\end{tabular}

a. Predictors: (Constant), OverallHeight, GlazingArea, WallArea, RelativeCompactness, RoofArea, GlazingAreaDistribution

The significance of the network's model-predicted value in relation to the different values of the independent variable is then reflected by the independent variable importance. Table 5 shows the coefficients values for MLR analysis. Based on Table 5 , the significant variables are Overall Height ( $p$ val=0.00), Glazing Area ( $p$-val=0.00), Wall Area ( $p$-val=0.038), Relative Compactness ( $p$-val=0.00), Roof Area ( $p$-val=0.00), and Glazing Area Distribution ( $p$-val=0.04). The percentages of importance divided by the highest importance values yields the normalized importance. Table 6 shows the parameter estimates of the MLR-ANN used in this research, Table 7 tabulates the independent variable importance, and Figure 2 depicts the normalized importance analysis produced.

Table 5

Coefficients

\begin{tabular}{|c|c|c|c|c|c|}
\hline \multirow[t]{2}{*}{ Variables } & \multicolumn{2}{|c|}{ Unstandardized Coefficients } & \multirow{2}{*}{$\begin{array}{l}\text { Standardized } \\
\text { Coefficients Beta }\end{array}$} & \multirow[t]{2}{*}{$\mathrm{t}$} & \multirow[t]{2}{*}{ Sig. } \\
\hline & $\mathrm{B}$ & Std. Error & & & \\
\hline (Constant) & 83.933 & 19.019 & & 4.413 & .000 \\
\hline OverallHeight & 4.170 & .338 & .724 & 12.345 & .000 \\
\hline GlazingArea & 19.933 & .813 & .263 & 24.503 & .000 \\
\hline WallArea & -.026 & .013 & -.114 & -2.074 & .038 \\
\hline RelativeCompactness & -64.774 & 10.283 & -.679 & -6.299 & .000 \\
\hline RoofArea & -.175 & .034 & -.781 & -5.115 & .000 \\
\hline GlazingAreaDistribution & .204 & .070 & .031 & 2.916 & .004 \\
\hline
\end{tabular}

Table 6

The Parameter Estimates

\begin{tabular}{|c|c|c|c|c|c|}
\hline \multirow[t]{3}{*}{ Predictor } & & \multicolumn{4}{|c|}{ Predicted } \\
\hline & & \multicolumn{3}{|c|}{ Hidden Layer 1} & \multirow{2}{*}{$\begin{array}{l}\text { Output Layer } \\
\text { HeatingLoad }\end{array}$} \\
\hline & & $H(1: 1)$ & $H(1: 2)$ & $H(1: 3)$ & \\
\hline \multirow[t]{7}{*}{ Input Layer } & (Bias) & -3.239 & -.277 & 1.100 & \\
\hline & OverallHeight & .655 & .223 & -1.958 & \\
\hline & GlazingArea & -.075 & -.146 & -.114 & \\
\hline & WallArea & 3.040 & -.388 & .081 & \\
\hline & RelativeCompactness & -.158 & -.646 & -.667 & \\
\hline & RoofArea & -2.090 & -.696 & -1.348 & \\
\hline & GlazingAreaDistribution & .050 & -.026 & .022 & \\
\hline \multirow[t]{4}{*}{ Hidden Layer 1} & (Bias) & & & & 1.088 \\
\hline & $H(1: 1)$ & & & & 1.282 \\
\hline & $H(1: 2)$ & & & & -1.686 \\
\hline & $H(1: 3)$ & & & & -1.555 \\
\hline
\end{tabular}


Table 7

The Independent Variable Importance

\begin{tabular}{lll}
\hline & Importance & $\begin{array}{l}\text { Normalized } \\
\text { Importance }\end{array}$ \\
\hline OverallHeight & .156 & $50.7 \%$ \\
GlazingArea & .064 & $20.8 \%$ \\
WallArea & .309 & $100.0 \%$ \\
RelativeCompactness & .269 & $87.1 \%$ \\
RoofArea & .193 & $62.4 \%$ \\
GlazingAreaDistribution & .009 & $2.9 \%$ \\
\hline
\end{tabular}

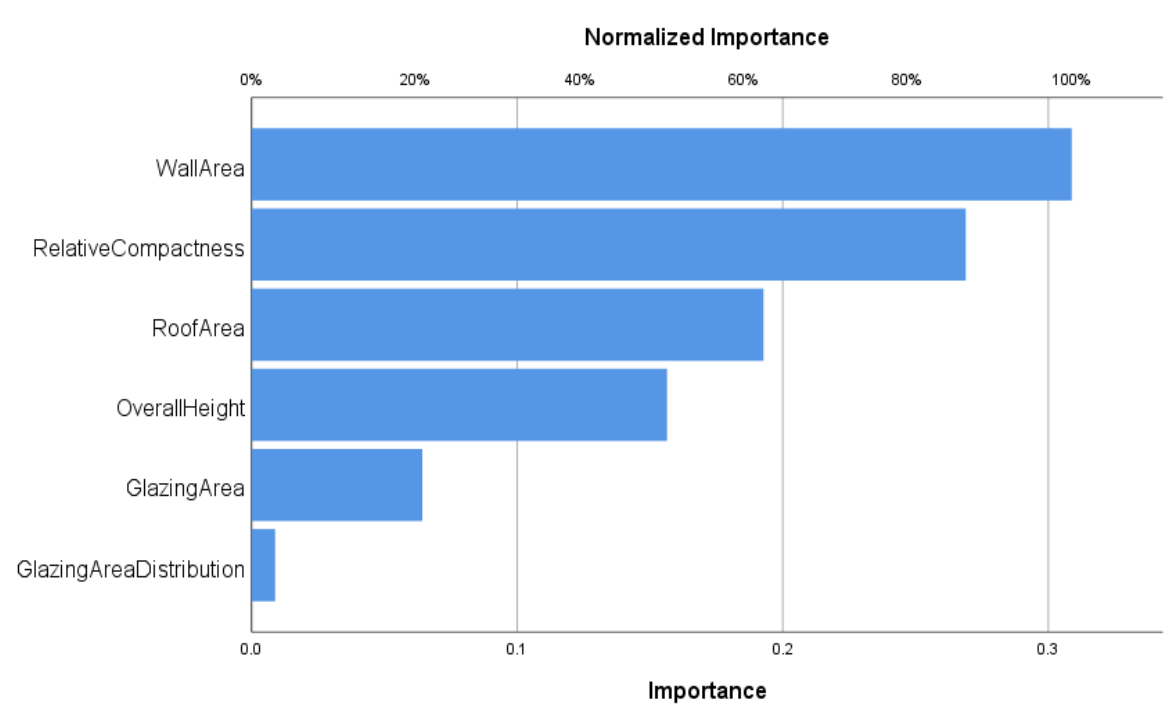

Fig. 2. Normalized Importance

Based on the Table 6 and Figure 2, the Wall Area was monitored to return an excellent percentage of normalized importance which is $100 \%$. The Relative Compactness, Roof Area, and Overall Height were also found to have the high effects on the $\mathrm{HL}$ of residential buildings which produced $87.1 \%$, $62.4 \%$, and $50 \%$ of normalized importance respectively. On the other hand, the Glazing Area and Glazing Area Distribution reflected the slightest effects on $\mathrm{HL}$ which are $20.8 \%$ and $2.9 \%$ normalized importance only.

In summary, the MLR-ANN model was used to estimate the contributing factors of $H L$ on residential buildings. The MSE, determination coefficients $R^{2}$, as well as the percentage of normalized importance analysis, were used to assess the statistical prediction capabilities of the MLR-ANN model. As a result, the MLR-ANN model's results revealed that the measured $R^{2}$ between the output and the desired data was good, with $R^{2}$ of 0.916 , a residual MSE of 8.600 , and a $100 \%$ normalized importance for Wall Area. Thus, it clearly signifies that the Wall Area is the most contributing factor towards HL, followed by the Relative Compactness, Roof Area, Overall Height, Glazing Area, and Glazing Area Distribution.

\section{Conclusions}

This paper investigates the effects of six input variables which are Overall Height, Glazing Area, Wall Area, Relative Compactness, Roof Area, and Glazing Area Distribution on one output variable, namely Heating Load (HL) of residential buildings. The Multiple Linear Regression and Artificial Neural Network (MLR-ANN) approaches were employed on the 768 dataset of residential buildings. The twolayer hyperbolic tangent-identity transfer functions with 6-3-1 configurations were identified as the 
best neural network model. Based on the findings of MLR-ANN analysis, it was found that the Wall Area is the most significant contributor to $\mathrm{HL}$, followed by Relative Compactness, Roof Area, Overall Height, Glazing Area, and Glazing Area Distribution. It is advised that HVAC (heating, ventilation, and air conditioning) systems need to installed in residential buildings to minimize energy use. Natural ventilation of vernacular design, and radiant heating and cooling systems is encouraged in buildings as it is a particularly effective and efficient way of ensuring thermal comfort within a structure.

\section{Acknowledgement}

The research was supported by Universiti Teknologi Mara Cawangan Melaka through the Teja Internal Grant 2021 (gdt2021/1-25).

\section{References}

[1] Soares, N., J. Bastos, L. Dias Pereira, A. Soares, A. R. Amaral, E. Asadi, E. Rodrigues et al. "A review on current advances in the energy and environmental performance of buildings towards a more sustainable built environment." Renewable and Sustainable Energy Reviews $77 \quad$ (2017): 845-860. https://doi.org/10.1016/i.rser.2017.04.027

[2] Vardoulakis, Sotiris, Chrysanthi Dimitroulopoulou, John Thornes, Ka-Man Lai, Jonathon Taylor, Isabella Myers, Clare Heaviside et al. "Impact of climate change on the domestic indoor environment and associated health risks in the UK." Environment international 85 (2015): 299-313. https://doi.org/10.1016/j.envint.2015.09.010

[3] Dean, Brian, John Dulac, Ksenia Petrichenko, and Peter Graham. "Towards zero-emission efficient and resilient buildings.: Global status report." Global Alliance for Buildings and Construction (GABC) (2017).

[4] Alam, Azimil Gani, Chang In Baek, and Hwataik Han. "Prediction and Analysis of Building Energy Efficiency Using Artificial Neural Network and Design of Experiments." In Applied Mechanics and Materials, vol. 819, pp. 541-545. Trans Tech Publications Ltd, 2016. https://doi.org/10.4028/www.scientific.net/AMM.819.541

[5] Tsanas, Athanasios, and Angeliki Xifara. "Accurate quantitative estimation of energy performance of residential buildings using statistical machine learning tools." Energy and Buildings 49 (2012): 560-567. https://doi.org/10.1016/j.enbuild.2012.03.003

[6] Bui, Xuan-Nam, Hossein Moayedi, and Ahmad Safuan A. Rashid. "Developing a predictive method based on optimized M5Rules-GA predicting heating load of an energy-efficient building system." Engineering with Computers 36, no. 3 (2020): 931-940. https://doi.org/10.1007/s00366-019-00739-8

[7] Sajjad, Muhammad, Samee Ullah Khan, Noman Khan, ljaz UI Haq, Amin Ullah, Mi Young Lee, and Sung Wook Baik. "Towards efficient building designing: Heating and cooling load prediction via multi-output model." Sensors 20, no. 22 (2020): 6419. https://doi.org/10.3390/s20226419

[8] Zhang, Qiang, Zhe Tian, Zhijun Ma, Genyan Li, Yakai Lu, and Jide Niu. "Development of the heating load prediction model for the residential building of district heating based on model calibration." Energy 205 (2020): 117949. https://doi.org/10.1016/i.energy.2020.117949

[9] Ding, Yan, Qiang Zhang, Tianhao Yuan, and Kun Yang. "Model input selection for building heating load prediction: A case study for an office building in Tianjin." Energy and Buildings 159 (2018): 254-270. https://doi.org/10.1016/i.enbuild.2017.11.002

[10] Roy, Sanjiban Sekhar, Pijush Samui, Ishan Nagtode, Hemant Jain, Vishal Shivaramakrishnan, and Behnam Mohammadi-Ivatloo. "Forecasting heating and cooling loads of buildings: A comparative performance analysis." Journal of Ambient Intelligence and Humanized Computing 11, no. 3 (2020): 1253-1264. https://doi.org/10.1007/s12652-019-01317-y

[11] Liu, Yanfeng, Xiaoxue Hu, Xi Luo, Yong Zhou, Dengjia Wang, and Sleiman Farah. "Identifying the most significant input parameters for predicting district heating load using an association rule algorithm." Journal of Cleaner Production 275 (2020): 122984. https://doi.org/10.1016/i.jclepro.2020.122984

[12] Ashouri, Araz, Zixiao Shi, and H. Burak Gunay. "Data-driven short-term load forecasting for heating and cooling demand in office buildings." In Journal of Physics: Conference Series, vol. 1343, no. 1, p. 012038. IOP Publishing, 2019. https://doi.org/10.1088/1742-6596/1343/1/012038

[13] Bacher, Peder, Henrik Madsen, Henrik Aalborg Nielsen, and Bengt Perers. "Short-term heat load forecasting for single family houses." Energy and Buildings 65 (2013): 101-112. https://doi.org/10.1016/i.enbuild.2013.04.022

[14] Dagdougui, Hanane, Fatemeh Bagheri, Hieu Le, and Louis Dessaint. "Neural network model for short-term and veryshort-term load forecasting in district buildings." Energy and Buildings 203 (2019): 109408. https://doi.org/10.1016/i.enbuild.2019.109408 
[15] Ahmad, Tanveer, and Huanxin Chen. "Short and medium-term forecasting of cooling and heating load demand in building environment with data-mining based approaches." Energy and Buildings 166 (2018): 460-476. https://doi.org/10.1016/j.enbuild.2018.01.066

[16] Koschwitz, Daniel, Eric Spinnraeker, Jérôme Frisch, and Christoph van Treeck. "Long-term urban heating load predictions based on optimized retrofit orders: A cross-scenario analysis." Energy and Buildings 208 (2020): 109637. https://doi.org/10.1016/j.enbuild.2019.109637

[17] Bagheri-Esfeh, Hamed, Hamed Safikhani, and Sadegh Motahar. "Multi-objective optimization of cooling and heating loads in residential buildings integrated with phase change materials using the artificial neural network and genetic algorithm." Journal of Energy Storage 32 (2020): 101772. https://doi.org/10.1016/i.est.2020.101772

[18] Tawaf, Mohamed Khatif, Mohd For Mohd Amin, Doris Asmani Mat Yusof, Shahrul Nizam Mohamad, and Diana Che Lat. "Sandstone rippability assessment based on specific energy relationship with tensile strength and surface hardness." Journal of Advanced Research in Applied Sciences and Engineering Technology 10, no. 1 (2018): 25-33.

[19] Kalogirou, Soteris A. "Artificial neural networks in energy applications in buildings." International Journal of LowCarbon Technologies 1, no. 3 (2006): 201-216. https://doi.org/10.1093/ijlct/1.3.201

[20] Zhou, Guofeng, Hossein Moayedi, Mehdi Bahiraei, and Zongjie Lyu. "Employing artificial bee colony and particle swarm techniques for optimizing a neural network in prediction of heating and cooling loads of residential buildings." Journal of Cleaner Production 254 (2020): 120082. https://doi.org/10.1016/i.jclepro.2020.120082

[21] Escandón, Rocío, Fabrizio Ascione, Nicola Bianco, Gerardo Maria Mauro, Rafael Suárez, and Juan José Sendra. "Thermal comfort prediction in a building category: Artificial neural network generation from calibrated models for a social housing stock in southern Europe." Applied Thermal Engineering 150 (2019): 492-505. https://doi.org/10.1016/j.applthermaleng.2019.01.013

[22] Al-Habaibeh, Amin, Arijit Sen, and John Chilton. "Evaluation tool for the thermal performance of retrofitted buildings using an integrated approach of deep learning artificial neural networks and infrared thermography." Energy and Built Environment 2, no. 4 (2021): 345-365. https://doi.org/10.1016/j.enbenv.2020.06.004

[23] Thiangchanta, Surasit, and Chatchawan Chaichana. "The multiple linear regression models of heat load for airconditioned room." Energy Reports 6 (2020): 972-977. https://doi.org/10.1016/j.egyr.2020.11.090

[24] Gao, Xiaoyu, Chengying Qi, Guixiang Xue, Jiancai Song, Yahui Zhang, and Shi-ang Yu. "Forecasting the Heat Load of Residential Buildings with Heat Metering Based on CEEMDAN-SVR." Energies 13, no. 22 (2020): 6079. https://doi.org/10.3390/en13226079

[25] Li, Xinyi, and Runming Yao. "A machine-learning-based approach to predict residential annual space heating and cooling loads considering occupant behaviour." Energy $212 \quad$ (2020): 118676. https://doi.org/10.1016/i.energy.2020.118676

[26] Rodriguez, Jose, and Nelson Fumo. "Zoned heating, ventilation, and air-conditioning residential systems: $A$ systematic review." Journal of Building Engineering (2021): 102925. https://doi.org/10.1016/j.jobe.2021.102925

[27] Bekesiene, S., and S. Hoskova-Mayerova. "Automatic model building for binary logistic regression by using SPSS 20 software." In Proceedings of the 18th Conference on Applied Mathematics APLIMAT, pp. 31-40. 2019.

[28] Hošková-Mayerová, Šárka, Václav Talhofer, Pavel Otřísal, and Marian Rybanský. "Influence of weights of geographical factors on the results of multicriteria analysis in solving spatial analyses." ISPRS International Journal of Geo-Information 9, no. 8 (2020): 489. https://doi.org/10.3390/ijgi9080489

[29] Hosseinzadeh, Ahmad, Mansour Baziar, Hossein Alidadi, John L. Zhou, Ali Altaee, Ali Asghar Najafpoor, and Salman Jafarpour. "Application of artificial neural network and multiple linear regression in modeling nutrient recovery in vermicompost under different conditions." Bioresource Technology $303 \quad$ (2020): 122926. https://doi.org/10.1016/i.biortech.2020.122926

[30] Omairi, Amzar, and Z. H. Ismail. "Modeling battery state of charge in wireless sensor networks based on structured multi-layer perceptron." Journal of Advanced Research in Applied Sciences and Engineering Technology 5, no. 2 (2016): 36-45.

[31] Fath, Aref Hashemi, Farshid Madanifar, and Masood Abbasi. "Implementation of multilayer perceptron (MLP) and radial basis function (RBF) neural networks to predict solution gas-oil ratio of crude oil systems." Petroleum 6, no. 1 (2020): 80-91. https://doi.org/10.1016/j.pet/m.2018.12.002

[32] Ibrahim, Shafaf, Saadi Ahmad Kamaruddin, Nur Nabilah Abu Mangshor, and Ahmad Firdaus Ahmad Fadzil. "Performance evaluation of multi-layer perceptron (MLP) and radial basis function (RBF): COVID-19 spread and death contributing factors." International Journal of Advanced Trends in Computer Science and Engineering 9, no. 1.4 (2020): 625-631. https://doi.org/10.30534/ijatcse/2020/8791.42020

[33] Mangshor, Nur Nabilah Abu, Shafaf Ibrahim, Nurbaity Sabri, and Saadi Ahmad Kamaruddin. "Students' learning habit factors during COVID-19 pandemic using multilayer perceptron (MLP)." International Journal of Advanced Technology and Engineering Exploration 8, no. $74 \quad$ (2021): $190-198$. https://doi.org/10.19101/IJATEE.2020.S1762140 
[34] Ibrahim, Shafaf, Saadi Ahmad Kamaruddin, N. N. Abu Mangshor, and A. F. Ahmad Fadzil. "A study of Covid-19 spread and death contributing factors in America Using Multi-Layer Perception (MLP) and Radial Basis Function (RBF)." European Journal of Molecular and Clinical Medicine 8, no. 2 (2021): 144-158.

[35] López-Aguilar, Kelvin, Adalberto Benavides-Mendoza, Susana González-Morales, Antonio Juárez-Maldonado, Pamela Chiñas-Sánchez, and Alvaro Morelos-Moreno. "Artificial neural network modeling of greenhouse tomato yield and aerial dry matter." Agriculture 10, no. 4 (2020): 97. https://doi.org/10.3390/agriculture10040097

[36] Ennouri, Karim, Rayda Ben Ayed, Mohamed Ali Triki, Ennio Ottaviani, Maura Mazzarello, Fathi Hertelli, and Nabil Zouari. "Multiple linear regression and artificial neural networks for delta-endotoxin and protease yields modelling of Bacillus thuringiensis." 3 Biotech 7, no. 3 (2017): 1-13. https://doi.org/10.1007/s13205-017-0799-1

[37] Van Liew, M. W., J. G. Arnold, and J. D. Garbrecht. "Hydrologic simulation on agricultural watersheds: Choosing between two models." Transactions of the ASAE 46, no. 6 (2003): 1539. https://doi.org/10.13031/2013.15643 